\section{(6) OPEN ACCESS}

\title{
Determinants of team-sport performance: implications for altitude training by team-sport athletes
}

\author{
David J Bishop, ${ }^{1}$ Olivier Girard ${ }^{2}$
}

1 Institute of Sport, Exercise and Active Living (ISEAL), College of Sport and Exercise Science, Victoria University, Melbourne, Australia

${ }^{2}$ Research and Education Centre, Aspetar-Qatar Orthopaedic and Sports Medicine Hospital, Doha, Qatar

\section{Correspondence to}

Professor David Bishop, Institute of Sport, Exercise and Active Living (ISEAL),

College of Sport and Exercise Science, Victoria University,

Melbourne, VIC 8001,

Australia;

David.Bishop@vu.edu.au

Accepted 13 September 2013

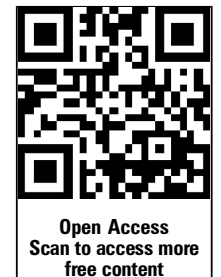

To cite: Bishop DJ, Girard O. Br J Sports Med 2013;47:i17-i21.

\section{ABSTRACT}

Team sports are increasingly popular, with millions of participants worldwide. Athletes engaged in these sports are required to repeatedly produce skilful actions and maximal or near-maximal efforts (eg, accelerations, changes in pace and direction, sprints, jumps and kicks), interspersed with brief recovery intervals (consisting of rest or low-intensity to moderate-intensity activity), over an extended period of time (1-2 h). While performance in most team sports is dominated by technical and tactical proficiencies, successful team-sport athletes must also have highly-developed, specific, physical capacities. Much effort goes into designing training programmes to improve these physical capacities, with expected benefits for team-sport performance. Recently, some team sports have introduced altitude training in the belief that it can further enhance team-sport physical performance. Until now, however, there is little published evidence showing improved team-sport performance following altitude training, despite the often considerable expense involved. In the absence of such studies, this review will identify important determinants of team-sport physical performance that may be improved by altitude training, with potential benefits for team-sport performance. These determinants can be broadly described as factors that enhance either sprint performance or the ability to recover from maximal or near-maximal efforts. There is some evidence that some of these physical capacities may be enhanced by altitude training, but further research is required to verify that these adaptations occur, that they are greater than what could be achieved by appropriate sea-level training and that they translate to improved team-sport performance.

\section{INTRODUCTION}

Team sports are increasingly popular, with millions of participants worldwide. Athletes engaged in these sports are required to repeatedly produce skilful actions and maximal or near-maximal efforts (eg, accelerations, changes in pace and direction, sprints, jumps and kicks), in a semistochastic fashion, interspersed with brief recovery intervals (consisting of rest or low-intensity to moderate-intensity activity), with and without the ball/puck, over an extended period of time (1-2 h). The physical demands are therefore complex, requiring athletes to have highly developed speed, agility, muscular strength and power and endurance. Athletes also require the ability to repeatedly execute complex motor skills (eg, passing, defending and tackling) under pressure and while fatigued. ${ }^{12}$

During competitive, field-based team sports, elite athletes may cover $8-14 \mathrm{~km}$ at an average intensity of $\sim 85-90 \%$ of their maximal heart rate $\left(\mathrm{HR}_{\max }\right)$ or $75-80 \%$ of their maximal oxygen uptake $\left(\mathrm{VO}_{2 \max }\right)$, with marked differences related to playing standard and position. ${ }^{3-9}$ This suggests that a well-developed aerobic energy system is an important physiological determinant of team-sport physical performance. The observation that more than 150 different, brief, intense actions may be performed in a team-sport match, and that athletes may record moderately-large blood $(2-14 \mathrm{mM})$ and muscle lactate values $(\sim 15 \mathrm{mmol} / \mathrm{kg}$ dry weight.) after intense periods of play, indicates that the rate of anaerobic energy turnover is also high during periods of a match. ${ }^{70}$ Much effort goes into designing training programmes to improve these physiological capacities, with expected benefits for team-sport performance.

Recently, some team sports have introduced altitude training (AT) ${ }^{\mathrm{i}}$ in the belief that it can enhance their sea-level, match-related physical performance. Until now, however, there is scant published evidence showing improved team-sport performance following AT, despite the often considerable expense involved. ${ }^{11}$ In the absence of such studies, this review will identify important physiological determinants of team-sport physical performance and briefly discuss the evidence that these may be improved by simulated or natural AT. It is beyond the scope of this review to identify technical and tactical abilities that may influence team-sport performance and that might be affected by AT. It is also beyond the scope of this review to discuss how reductions in air density experienced during hypobaric hypoxia may affect factors such as ball flight (air density reduces by about $10 \%$ for every $1000 \mathrm{~m}$ increase in altitude and will affect flight characteristics). ${ }^{12}$

\section{Physiological factors determining team-sport physical performance}

A better understanding of the physiological factors associated with team-sport physical performance is arguably the first step in order to assess whether AT may play a role in enhancing team-sport performance. As most team sports require athletes to regularly repeat short, high-intensity efforts, interspersed with longer intervals of submaximal exercise, these physiological factors can be broadly described as

${ }^{\mathrm{i}}$ For the purpose of this review, altitude training refers to living and/or training at a natural or simulated altitude (eg, live high-train low, live high-train high). It does not include intermittent hypoxic training, which has been the subject of recent reviews. 
factors that affect either sprint performance or the ability to recover from maximal or near-maximal efforts (figure 1). It should be noted, however, that many of these factors may also influence other aspects of team-sport physical performance (eg, explosive power may also influence jump performance).

\section{Sprint performance}

Sprinting, defined as a running velocity above a lower limit ranging from 19 to $25 \mathrm{~km} / \mathrm{h}$, amounts to $5-10 \%$ of the total distance covered during a match and corresponds to $1-3 \%$ of match time in rugby league and soccer (football). ${ }^{13}{ }^{14}$ The importance of sprint performance for team-sport athletes is highlighted by the observation that straight sprinting is the most frequent action preceding a goal in football (soccer). ${ }^{15}$ It has also been estimated that an $\sim 0.8 \%$ impairment in sprint speed would have a substantial detrimental effect on the likelihood of a player losing possession of the ball against an opponent, when both players sprint for the ball. ${ }^{16}$ In addition, mean sprint speed during a repeated-sprint ability (RSA test; which is strongly correlated with peak speed ${ }^{17-20}$ ) has been correlated with total sprint distance during a professional football match. ${ }^{21}$ While further research is required, there is emerging evidence that sprint performance is an important determinant of team-sport performance.

Despite its importance, and possibly due to an emphasis on the effects of AT on endurance performance, ${ }^{11}$ there has been scant research into the effects of AT on sprint performance. In the two published studies that we are aware of, AT was reported to result in a greater improvement in $150 \mathrm{~m}^{22}$ and $400 \mathrm{~m}^{23}$ sealevel running performance compared to sea-level training. However, as the physiological and metabolic demands of these running distances will differ from the types of sprints typically performed by team-sport athletes $(<6 \mathrm{~s})$, further research is clearly required to investigate the effects of AT on brief sprint performance and its determinants.

\section{Determinants of sprint performance}

In simple terms, sprint performance is determined by stride length and stride frequency (figure 1). To improve speed, an increase in one or both of these parameters must occur within the context of sound technique. Improvements in stride length, and hence speed, are intimately linked to improvements in power-which is directly related to strength, elastic strength and dynamic flexibility (the ability to move the appropriate joints through a large range of motion at high speeds). ${ }^{24}$ Power has also been related to the ability to supply ATP at a fast rate and to the percentage of fast-twitch fibres. ${ }^{25}$ Sprint performance is also determined by stride frequency, which is related to factors such as intramuscular coordination. We summarise below the research investigating the effects of AT on these determinants of sprint performance.

\section{ATP supply}

Maximal sprint efforts rely on a fast and constant turnover of ATP, powered by phosphocreatine (PCr) breakdown and anaerobic glycolysis. ${ }^{26}$ As such, team-sport athletes may be able to improve their sprint performance if they are able to enhance their ability to deplete large amounts of high-energy phosphates at a fast rate (ie, their anaerobic capacity). ${ }^{27}$ Anaerobic performance lasting $30 \mathrm{~s}$ or less on either a cycle ergometer (Wingate test $^{28-30}$ ) or a non-motorised treadmill ${ }^{31} 32$ is generally not adversely affected at altitude due to enhanced anaerobic energy release (ie, higher oxygen deficit or muscular lactate concentration), ${ }^{28}{ }^{30}$ to compensate for the reduced aerobic ATP production. A high rate of anaerobic energy release during exercise has been proposed to be an important stimulus to increase anaerobic capacity. ${ }^{33}$ It could therefore be hypothesised that this lower rate of oxygen delivery to muscles when training at altitude would increase the flux through the anaerobic energy systems and lead to greater improvements in anaerobic capacity. In support of this assumption, increases in maximal accumulated oxygen deficit have been reported either after 15 days spent at $2650 \mathrm{~m}$ and training at $610 \mathrm{~m}\left(10 \%{ }^{34}\right)$ or after 14 nights spent at $2100 \mathrm{~m}$ and training at $2700 \mathrm{~m}\left(29 \%{ }^{35}\right)$. As training has not been reported to increase PCr breakdown during high-intensity exercise, ${ }^{36-38}$ these increases in maximal accumulated oxygen deficit (an indirect measure of anaerobic capacity ${ }^{39}$ ) can most likely be attributed to increases in the rate of anaerobic glycolysis.

There are conflicting results concerning the effects of AT on glycolytic adaptations. For example, greater increases in phosphofructokinase (PFK) activity have been reported when sprint

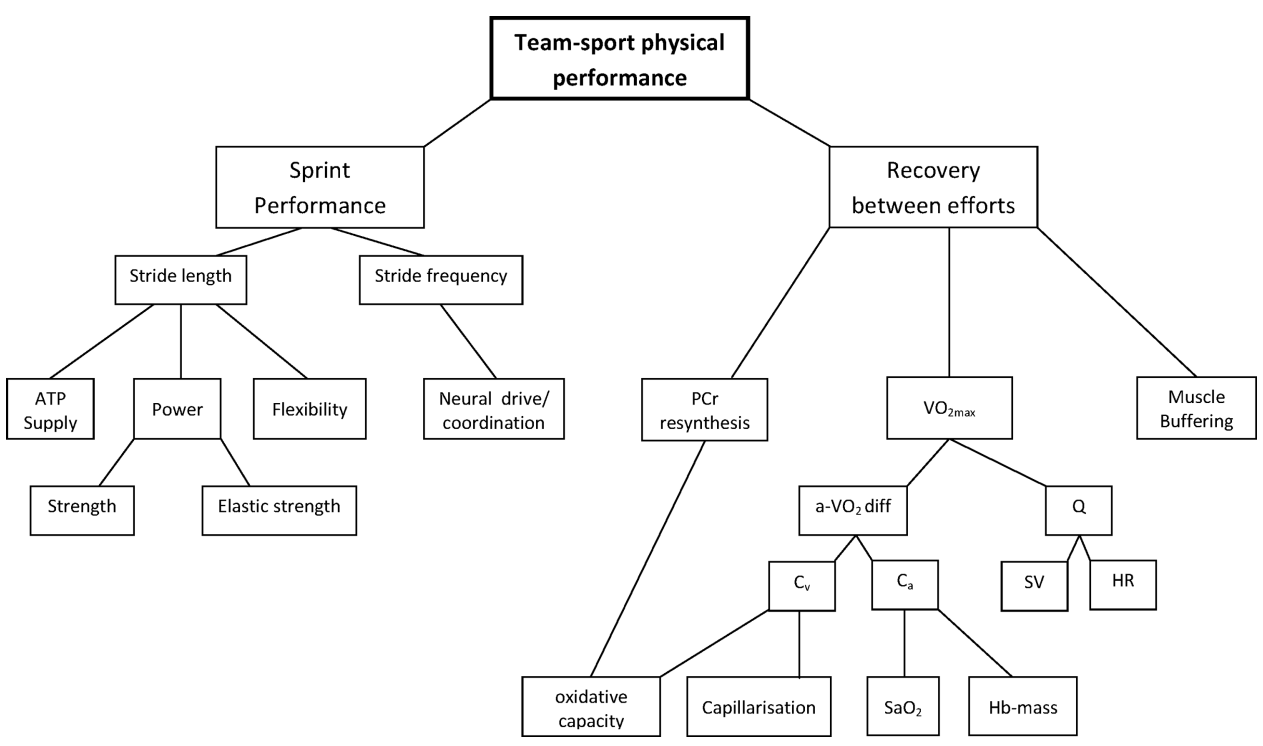

Figure 1 A summary of the main physiological factors that affect team-sport physical performance; these can be broadly described as factors that affect either sprint performance or the ability to recover from maximal or near-maximal efforts. 
interval training is performed in normobaric hypoxia $(\sim 3200 \mathrm{~m})$, compared to normoxia. ${ }^{40}$ In contrast, research involving endurance athletes has reported a decrease in PFK activity after either a 'live high-train low' intervention $(2 \times 8 \mathrm{~h} /$ week for 3 weeks; hypoxic dose $<50 \mathrm{~h})^{41}$ or training in a hypobaric chamber (4-5 sessions/week for 3-4 weeks at $\sim 2300 \mathrm{~m}){ }^{42}$ These negative findings can probably be attributed to the study design whereby endurance athletes performed training at altitude that consisted primarily of aerobic workouts. In addition, the low level of hypoxia used in some of these studies $(<2500 \mathrm{~m})$ may not have been sufficient to elicit an additional activation of anaerobic pathways beyond that observed in normoxia. ${ }^{43}$ While further research is required, it appears that team-sport athletes may be able achieve greater increases in anaerobic capacity, and possibly sprint performance, by performing sprint training at altitude.

\section{Strength}

Maximal muscle strength can be defined as the maximal force a muscle or muscle group can generate at a specific velocity. ${ }^{44}$ It appears that hypoxia alone is insufficient to induce muscle hypertrophy, increase muscle strength (one repetition maximum, $1 \mathrm{RM}$ ) or improve sea-level (repeated) sprint performance. ${ }^{45}$ However, it has been hypothesised that resistance training combined with systemic hypoxia may lead to greater improvements in muscle strength. ${ }^{4546}$ Resistance training with systemic hypoxia causes a reduction in the concentration of oxygen in the blood and tissue, inducing greater accumulation of metabolites (blood lactate) and anabolic hormones (eg, growth hormone). ${ }^{47}$ Training under these circumstances would also result in an accelerated recruitment of type II motor units, potentially increasing the stress on these units and subsequently producing adaptation in the form of hypertrophy of these motor units. 4849

Until now, only a few studies have investigated whether resistance training performed in hypoxia is more efficient at improving maximal strength and eventually single-sprint performance than similar training in normoxia. In one study, low-resistance exercise (6 sets of 25 repetitions at 30\% 1RM, 3 times/week for 4 weeks) combined with hypoxia (fractional inspired oxygen, $\mathrm{FiO}_{2}=0.12$, $\sim 4000 \mathrm{~m}$ ) had no additional effect on maximal strength compared to identical exercise completed under normoxic conditions. ${ }^{50}$ In contrast, another research group has reported larger increases in strength following resistance training performed in hypoxia versus normoxia. ${ }^{46}{ }^{51}$ In the one available study involving a team-sport population (ie, female netball athletes), resistance training under hypoxic conditions (5 weeks of training of the knee flexor and extensor muscles in which low-load resistance exercise ( $20 \%$ of $1 \mathrm{RM}$ ) was combined with hypoxic air to generate blood oxyhaemoglobin levels of approximately $80 \%$ ) not only improved muscle strength (15\%) and muscle hypertrophy (6\%), but also induced faster (4\%) 5 and $10 \mathrm{~m}$ sprint times. ${ }^{51}$ Thus, while further research is required, especially incorporating resistance-training protocols more specific to those used by team-sport athletes, there is emerging evidence that resistance training at altitude may lead to greater improvements in muscle strength. Future studies should also determine which form of resistance training (maximal vs explosive muscle strength) and which hypoxic dose is best for maximising improvements in muscle strength. As the orientation of the total force applied to the supporting ground during a sprint acceleration is more important to performance than its amount, ${ }^{52}$ future AT studies should also determine whether any enhancements in maximal strength translate into a better force application technique and better sprint performance.

\section{Elastic strength}

Elastic strength, or reactive strength, is dependent on the stretch-shortening cycle and is the ability to exert maximal force during a high-speed movement ${ }^{53}$; elastic strength has been shown to be an important determinant of sprint performance. ${ }^{54}$ To our knowledge, however, there is no published research that has directly investigated the effects of AT on elastic strength. Future AT studies, incorporating team-sport-specific speed, strength and power training, performed in hypoxia, should consider including measures of elastic strength to address this knowledge gap.

\section{Neural drive/coordination}

Improved intramuscular coordination, leading to increases in stride frequency, should theoretically improve sprint performance. $^{24}$ The question of whether training at altitude can lead to greater improvements in stride frequency during sprinting has not been specifically addressed. However, the scientific literature, ${ }^{55}$ mathematical models ${ }^{5657}$ and performance results (1968 Olympic Games in Mexico) all suggest that sprint performance is enhanced during acute exposure to natural altitude, which has been attributed to the lower air density at altitude. ${ }^{12}$ This raises the intriguing possibility of developing over-speed routines when training at natural altitude to improve intramuscular coordination and stride frequency. In support of this, 2 weeks of strength and speed training at a natural altitude of $1860 \mathrm{~m}$ significantly improved $150 \mathrm{~m}$ sprint performance in five-national level sprinters, compared to a control group that trained simultaneously according to a similar programme at sea level. ${ }^{22}$ However, as this study did not specifically measure changes in stride frequency, or recruit team-sport athletes, more research is required.

Another important consideration for team-sport athletes is that the ability to repeat sprint performance has been associated with the ability to maintain faster stride frequencies, through retaining higher vertical stiffness. ${ }^{58}$ Mounting evidence, gathered from laboratory-based studies, suggests that biomechanical manifestations of fatigue are likely to be driven, at least partially, by hypoxia severity-dependent reductions in neural drive to the active musculature ${ }^{60}$; this is presumably the result of hypoxia-induced increased levels of intramuscular metabolites known to stimulate group III-IV muscle afferents (ie, accelerated development of peripheral fatigue) at moderate-to-high hypoxic levels (simulated altitudes $<4000 \mathrm{~m}$ ). ${ }^{62}$ At higher altitudes, the exaggerated development of central fatigue is primarily determined by a stronger reflex inhibition due to brain hypoxia. ${ }^{63}$ These heights, however, are clearly not relevant for team-sport AT purposes; that is, if too severe, hypoxia compromises training quality and hence counteracts the possible benefits to be derived from the greater stimuli to adapt. Although chronic altitude exposure (a 14-day exposure at $5260 \mathrm{~m}$ ) has the potential to attenuate the development of central fatigue during continuous, whole body exercise, ${ }^{64}$ whether a comparable response of the central nervous system can occur during high-intensity intermittent exercises after training at heights similar to those commonly used by team-sport players $(1500-3600 \mathrm{~m})$ is currently unknown. Although scientific support is currently lacking, it could also be that a hypoxia-induced improvement in the central motor drive resulting from AT may improve musculoskeletal stiffness regulation (ie, less energy wasted on braking forces and minimal vertical oscillation of the centre of mass), leading to a faster stride frequency and thereby improved sealevel repeated-sprint performance. 
Recovery between efforts Maximal oxygen uptake

Given the total distance travelled in a match, the relatively high average match intensity and the necessity to recover from brief, high-intensity activities, it is generally believed that high aerobic fitness is important for team-sport success. The most widely accepted measure of aerobic fitness is the $\mathrm{VO}_{2 \max }$, which represents the maximum rate at which aerobic metabolism can supply energy. ${ }^{65}$ In support of the importance of $\mathrm{VO}_{2 \max }$, studies have reported a correlation between $\mathrm{VO}_{2 \max }$ and the distance covered during team sports. ${ }^{66-68}$ It has also been reported that participants with a greater $\mathrm{VO}_{2 \max }$ are better able to maintain power outputs/sprint times during a repeated-sprint exercise and that there are moderate correlations $(\mathrm{r}=-0.20$ to -0.75$)$, not always significant, between $\mathrm{VO}_{2 \max }$ and performance drop-off indices. ${ }^{69-77}$ While some studies have reported increases in $\mathrm{VO}_{2 \max }$ following $\mathrm{AT}^{78-80}$ this is not a universal finding, especially in well-trained athletes. ${ }^{34} 81$

As indicated by the Fick equation, $\mathrm{VO}_{2 \max }$ is determined by central and peripheral factors. Until now, however, there has been limited research investigating the relationship between the central and peripheral determinants of $\mathrm{VO}_{2 \max }$ and team-sport physical performance. In one of the few studies, McMahon and Wenger $^{82}$ reported a weak correlation between cardiac output and the maintenance of power output during intermittent sprint exercise. While further research is required, it seems unlikely that increases in cardiac output will contribute to improvements in team-sport physical performance following AT.

The dominant factors explaining the association between $\mathrm{VO}_{2 \max }$ and team-sport physical performance appear to be peripherally located. ${ }^{82}$ In particular, the importance of the peripheral component of $\mathrm{VO}_{2 \max }$ is highlighted by the similar relationship between the arteriovenous oxygen difference $\left(\mathrm{a}-\mathrm{VO}_{2}\right.$ diff) and $\mathrm{VO}_{2 \max }$ and the ability to maintain power output during brief, intermittent sprints. ${ }^{82}$ This suggests that adaptations at the tissue level (eg, muscle oxidative capacity, capillarisation, haemoglobin mass) may be important determinants of the ability to frequently perform high-intensity activities during a team sport. ${ }^{83}$ In support of this, it has been reported that the fatigue index during repeated-sprint exercise was inversely correlated with maximal ADP-stimulated mitochondrial respiration measured directly on muscle fibres ${ }^{84}$ that capillary density was significantly related to recovery following a bout of maximal knee extensions ${ }^{85}$ and that giving erythropoietin resulted in a reduced accumulation of anaerobic metabolites in the blood following an intermittent sprint task. ${ }^{86}$ Further research is required, however, to establish the relationship between these peripheral factors and actual team-sport physical performance.

Despite the need for further team-sport-specific research, there is evidence that some of these peripheral factors can be improved by AT. Compared to sea-level training, 'live high-train low' AT has been reported to increase the a-VO ${ }_{2}$ diff. $^{78}$ In contrast, research suggests that short-duration $(<4$ week) 'live hightrain low' AT protocols do not increase capillarisation. ${ }^{87-89}$ However, training under normobaric hypoxic compared to normoxic conditions has been reported to result in greater increases in capillary density in one study, ${ }^{90}$ but not another. ${ }^{91}$ The effects of AT on mitochondrial adaptations remain unresolved. Mitochondrial respiration has been reported to diminish following 28 days of exposure to $\sim 3500 \mathrm{~m},{ }^{92}$ to remain unchanged following 9-11 days of exposure to $\sim 4500 \mathrm{~m}^{93}$ or to increase following 19 days of exposure to $\sim 3200 \mathrm{~m}$ (Bishop et al unpublished research). It is now established that long-term ( $>4$ week), but not short-term $(<4$ week $),{ }^{94}$ exposure to extreme $(>5500 \mathrm{~m})$ environmental hypoxia decreases the mitochondrial content of muscle fibres. ${ }^{95}$ However, compared to normoxic training, training under hypoxic conditions $(\sim 2000-4000 \mathrm{~m})$ has been reported to result in greater increases in citrate synthase activity ${ }^{9196}$ (citrate synthase is an enzyme that is exclusively located in the mitochondria ${ }^{97}$ and is strongly correlated with mitochondrial content ${ }^{98}$ ).

While there is some controversy, ${ }^{99} 100$ increases in haemoglobin mass $\left(\mathrm{Hb}_{\text {mass }}\right)$ are often reported following different types of AT, assuming an appropriate 'hypoxic dose' ( $300 \mathrm{~h}) .^{78} 79101$ Also, as the magnitude of haemoglobin $(\mathrm{Hb})$ increase has been suggested to be related to baseline $\mathrm{Hb}_{\text {mass, }},{ }^{102}$ team-sport athletes may be more likely to present increased $\mathrm{Hb}_{\text {mass }}$ in response to AT than elite cyclists. Even though increases in $\mathrm{Hb}_{\text {mass }}$ do not necessarily lead to improvements in $\mathrm{VO}_{2 \max },{ }^{99}$ there may be benefits for aerobic metabolism through the compensatory decrease in blood flow which may slow the mean blood transit time and improve the exchange of gases, substrates and metabolites. ${ }^{103}$ Thus, while there is emerging evidence that many of the peripheral determinants of $\mathrm{VO}_{2 \max }$ can be improved by either living and/or training under hypoxic conditions, further research is required to optimise the hypoxic stimulus and to investigate the effects of these changes on subsequent team-sport-related physical performance.

\section{Phosphocreatine resynthesis rate}

We are unaware of studies directly investigating the influence of the PCr resynthesis rate on team-sport physical performance. Nonetheless, there is good evidence that PCr resynthesis is an important determinant of the ability to recover single-sprint and repeated-sprint performance. ${ }^{104-108}$ This is supported by the observation that occlusion of the circulation to one leg prevents $\mathrm{PCr}$ resynthesis and reduces total work in subsequent sprints. ${ }^{109}$ The importance of $\mathrm{PCr}$ resynthesis for intermittent sprint performance is further supported by research demonstrating that creatine supplementation (which increases the PCr resynthesis rate $^{110}$ ) improves multiple-sprint performance, especially when the recovery between sprints ranges from $50-120 \mathrm{~s}^{111-114}$ and also improves some $20 \mathrm{~m}$ sprints and agility tasks during an exercise protocol designed to simulate match play in female football (soccer) players. ${ }^{115}$

The importance of the PCr resynthesis rate for the ability to recover from high-intensity exercise suggests that future studies should investigate the influence on AT on the rate of $\mathrm{PCr}$ resynthesis in team-sport athletes. It has been reported that the $\mathrm{PCr}$ resynthesis rate is positively correlated with citrate synthase activity ${ }^{116}$ and is reduced in patients with mitochondrial myopathies. ${ }^{117}$ Therefore, changes in the $\mathrm{PCr}$ resynthesis rate following AT are quite likely to closely reflect mitochondrial adaptations (which have been equivocal until now and also require further research).

\section{Buffer capacity}

In contrast to the good evidence that $\mathrm{VO}_{2 \max }$ and the $\mathrm{PCr}$ resynthesis rate are important determinants of team-sport physical performance, the importance of the hydrogen ion $\left(\mathrm{H}^{+}\right)$buffering is more controversial. A number of studies, ${ }^{118-123}$ but not all, ${ }^{124} 125$ have reported that increasing the blood buffer capacity is quite likely to improve repeated and intermittent sprint performance. However, the importance of muscle buffer capacity $(\beta \mathrm{m})$ is less convincing. Despite a persistent low muscle $\mathrm{pH}$, sprint power output has been reported to partially recover 6 min after a repeated-sprint test. ${ }^{104}$ Moreover, no significant 
correlations were noted between the recovery of $\mathrm{pH}$ and the recovery of power output during single or repeated sprints. ${ }^{104}$ Similarly, previous studies have shown that sprinting abilities were restored faster than muscle $\mathrm{pH}^{106126}$ and that the decline in sprint performance during a football (soccer) match was not correlated with muscle $\mathrm{pH} .{ }^{10}$ There has been one study that has reported a moderate correlation between $\beta \mathrm{m}$ and RSA, ${ }^{71}$ but to our knowledge no studies have correlated $\beta \mathrm{m}$ with team-sport physical performance.

Another way to assess the importance of $\beta \mathrm{m}$ is to assess team-sport-related physical performance before and after $\beta$-alanine supplementation. $\beta$-alanine is an important precursor of carnosine ( $\beta$-alanyl-L-histidine), ${ }^{127}$ an important muscle buffer that has been estimated to account for $\sim 10 \%$ of the total buffering capacity in the human vastus lateralis muscle. ${ }^{128} \beta$-alanine supplementation has been reported to improve Yo-Yo test performance ${ }^{129}$ (a test that correlates well with match physical performance in soccer players ${ }^{130131}$ ), but not intermittent sprint performance. ${ }^{132}$ Thus, while there is some evidence that $\beta \mathrm{m}$ may influence teamsport performance, more research is required.

Until now, five studies have investigated changes in $\beta \mathrm{m}$ in response to various forms of AT (with an average increase of $\sim 7 \%$; range $=0-18 \%) .{ }^{35} 4187133-135$ However, the response is quite variable with the smallest and the largest changes in $\beta \mathrm{m}$ reported following very similar altitude-training protocols by the same research group. ${ }^{133} 134$ Nonetheless, while this research suggests a possible benefit of AT on $\beta \mathrm{m}$, and therefore potentially team-sport physical performance, greater gains in $\beta \mathrm{m}$ have typically been reported in response to interval training. ${ }^{136} 137 \mathrm{It}$ is therefore difficult, based on current evidence, to justify the expenses associated with AT if the goal is to maximise improvements in $\beta \mathrm{m}$.

\section{CONCLUSIONS AND FUTURE DIRECTIONS}

There are many physiological qualities, important for team-sport performance, that could theoretically be improved by AT. However, much of this information is derived from studies conducted with endurance (individual) athletes. Further research is required to verify that these adaptations occur in team-sport athletes after AT and that these adaptations translate to improved team-sport physical performance. It will also be important to determine whether these adaptations are greater than what can be achieved by regular sea-level training. Given the many ways in which AT may be performed (eg, 'live high-train low', 'live hightrain high', 'live low-train high') and the different levels or conditions of hypoxic exposure possible, more research is required to optimise the AT stimulus to improve match-related physical performance and the different physiological determinants of teamsport physical performance identified in this review.

\section{What are the new findings?}

- This review summarises the physiological determinants of team-sport physical performance that could potentially be improved by altitude training.

- While the theoretical rationale is quite strong, there are very few published studies that have investigated changes in team-sport physical performance, or its determinants, in response to altitude training.

- There are many conflicting findings in the literature, which indicates the need to better control for diet, training and the altitude dose.
How might it impact on clinical practice in the near future?

This review highlights that there is theoretical support for the use of altitude training by team-sport athletes. However, it also highlights the need for further research to verify that altitude training can promote greater physiological adaptations than appropriate sea-level training and that these greater physiological adaptations translate to improved team-sport physical performance.

Contributors DB and OG contributed to the conception of this review, initial drafts and critical revision of the article for important intellectual content and final approval.

\section{Competing interests None.}

Provenance and peer review Not commissioned; externally peer reviewed.

Open Access This is an Open Access article distributed in accordance with the Creative Commons Attribution Non Commercial (CC BY-NC 3.0) license, which permits others to distribute, remix, adapt, build upon this work non-commercially, and license their derivative works on different terms, provided the original work is properly cited and the use is non-commercial. See: http://creativecommons.org/ licenses/by-nc/3.0/

\section{REFERENCES}

1 Rampinini E, Impellizzeri FM, Castagna C, et al. Effect of match-related fatigue on short-passing ability in young soccer players. Med Sci Sports Exerc 2008;40:934-42.

2 Rampinini E, Impellizzeri FM, Castagna C, et al. Technical performance during soccer matches of the Italian Series A league: effect of fatigue and competitive level. J Sci Med Sport 2009;12:227-33.

3 Spencer M, Bishop D, Dawson B, et al. Physiological and metabolic responses of repeated-sprint activities: specific to field-based team sports. Sports Med 2005; 35:1025-44.

4 Spencer $\mathrm{M}$, Lawrence $\mathrm{S}$, Rechichi $\mathrm{C}$, et al. Time-motion analysis of elite field hockey, with special reference to repeated-sprint activity. J Sports Sci 2004;22:843-50.

5 Spencer $M$, Rechichi $C$, Lawrence $S$, et al. Time-motion analysis of elite field hockey during several games in succession: a tournament scenario. I Sci Med Sport 2005;8:382-91.

6 Gabbett TJ. Science of rugby league football: a review. J Sports Sci 2005;23:961-76.

7 Bangsbo J, Mohr M, Krustrup P. Physical and metabolic demands of training and match-play in the elite football player. J Sports Sci 2006;24:665-74.

8 Aughey RJ. Increased high-intensity activity in elite Australian football finals matches. Int J Sports Physiol Perform 2011;6:367-79.

9 Aughey RJ. Widening margin in activity profile between elite and sub-elite Australian football: a case study. J Sci Med Sport 2013;16:382-6.

10 Krustrup P, Mohr M, Steensberg A, et al. Muscle and blood metabolites during a soccer game: implications for sprint performance. Med Sci Sports Exerc 2006;38:1165-74.

11 Billaut F, Gore CJ, Aughey RJ. Enhancing team-sport athlete performance: is altitude training relevant? Sports Med 2012;42:751-67.

12 Levine BD, Stray-Gundersen J, Mehta RD. Effect of altitude on football performance. Scand J Med Sci Sports 2008;18(Suppl 1):76-84.

13 Gabbett T, King T, Jenkins D. Applied physiology of rugby league. Sports Med 2008;38:119-38.

14 Nedelec M, McCall A, Carling C, et al. Recovery in soccer part I-post-match fatigue and time course of recovery. Sports Med 2012;42:997-1015.

15 Faude 0, Koch T, Meyer T. Straight sprinting is the most frequent action in goal situations in professional football. J Sports Sci 2012;30:625-31.

16 Paton $C D$, Hopkins WG, Vollebregt L. Little effect of caffeine ingestion on repeated sprints in team-sport athletes. Med Sci Sports Exerc 2001;33:822-5.

17 Mendez-Villanueva A, Hamer P, Bishop D. Fatigue responses during repeated sprints matched for initial mechanical output. Med Sci Sports Exerc 2007;39:2219-25.

18 Mendez-Villanueva A, Hamer P, Bishop D. Fatigue in repeated-sprint exercise is related to muscle power factors and reduced neuromuscular activity. Eur J App/ Physiol 2008;103:411-19.

19 Bishop DJ. Fatigue during intermittent-sprint exercise. Clin Exp Pharmacol Physiol 2012;39:836-41. 
20 Billaut F, Bishop DJ. Mechanical work accounts for sex differences in fatigue during repeated sprints. Eur J Appl Physiol 2012;112:1429-36.

21 Rampinini E, Bishop D, Marcora SM, et al. Validity of simple field tests as indicators of match-related physical performance in top-level professional soccer players. Int J Sports Med 2007:28:228-35.

22 Karvonen J, Peltola E, Saarela J, et al. Changes in running speed, blood lactic-acid concentration and hormone balance during sprint training performed at an altitude of 1860 meters. J Sports Med Phys Fitness 1990;30:122-6.

23 Nummela A, Rusko H. Acclimatization to altitude and normoxic training improve 400-m running performance at sea level. J Sports Sci 2000;18:411-19.

24 Ross $A$, Leveritt $M$, Riek $S$. Neural influences on sprint running: training adaptations and acute responses. Sports Med 2001;31:409-25.

25 Pereira J, Sargeant AJ, Rademaker A, et al. Myosin heavy chain isoform expression and high energy phosphate content in human muscle fibres at rest and post-exercise. J Physiol 996;496:583-8.

26 Gaitanos GC, Williams C, Boobis LH, et al. Human muscle metabolism during intermittent maximal exercise. J Appl Physiol 1993;75:712-19.

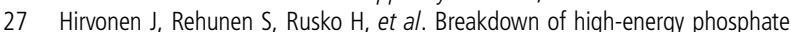
compounds and lactate accumulation during short supramaximal exercise. Eur J Appl Physiol 1987;56:253-9.

28 McLellan TM, Kavanagh MF, Jacobs I. The effect of hypoxia on performance during $30 \mathrm{~s}$ or $45 \mathrm{~s}$ of supramaximal exercise. Eur J Appl Physiol Occup Physiol 1990:60:155-61.

29 Grassi B, Mognoni P, Marzorati M, et al. Power and peak blood lactate at $5050 \mathrm{~m}$ with 10 and $30 \mathrm{~s}$ 'all out' cycling. Acta Physiol Scand 2001;172:189-94.

30 Calbet JAL, De Paz JA, Garatachea N, et al. Anaerobic energy provision does not limit Wingate exercise performance in endurance-trained subjects. J App/ Physiol 2003;94:668-76.

31 Weyand PG, Lee CS, Martinez-Ruiz R, et al. High-speed running performance is largely unaffected by hypoxic reductions in aerobic power. J App/ Physiol 1999;86:2059-64.

32 Ogawa T, Ohba K, Nabekura Y, et al. Intermittent short-term graded running performance in middle-distance runners in hypobaric hypoxia. Eur J Appl Physiol 2005:94:254-61.

33 Medbo Jl, Burgers S. Effect of training on the anaerobic capacity. Med Sci Sports Exerc 1990:22:501-7.

34 Roberts $A D$, Clark SA, Townsend NE, et al. Changes in performance, maximal oxygen uptake and maximal accumulated oxygen deficit after 5, 10 and 15 days of live high:train low altitude exposure. Eur J Appl Physiol 2003;88:390-5.

35 Mizuno M, Juel C, Bro-Rasmussen T, et al. Limb skeletal muscle adaptation in athletes after training at altitude. J App/ Physiol 1990;68:496-502.

36 Harmer AR, McKenna MJ, Sutton JR, et al. Skeletal muscle metabolic and ionic adaptations during intense exercise following sprint training in humans. J App/ Physiol 2000;89:1793-803.

37 Bishop D, Edge J, Thomas C, et al. Effects of high-intensity training on muscle lactate transporters and postexercise recovery of muscle lactate and hydrogen ions in women. Am J Physiol Regul Integr Comp Physiol 2008;295:R1991-8.

38 Mohr M, Krustrup P, Nielsen JJ, et al. Effect of two different intense training regimens on skeletal muscle ion transport proteins and fatigue development. $A m$ J Physiol Regul Integr Comp Physiol 2007;292:R1594-602.

39 Medbo Jl, Mohn AC, Tabata I, et al. Anaerobic capacity determined by maximal accumulated 02 deficit. J Appl Physiol 1988:64:50-60.

40 Puype J, Van Proeyen K, Raymackers J, et al. Sprint interval training in hypoxia stimulates glycolytic enzyme activity. Med Sci Sport Exerc 2013. In press. Published Online First: Epub Date. doi:10.1249/MSS.obo13e31829734ae ]|.

41 Basset FA, Joanisse DR, Boivin F, et al. Effects of short-term normobaric hypoxia on haematology, muscle phenotypes and physical performance in highly trained athletes. Exp Physiol 2006;91:391-402.

42 Terrados N, Melichna J, Sylven C, et al. Effects of training at simulated altitude on performance and muscle metabolic capacity in competitive road cyclists. Eur J Appl Physiol Occup Physiol 1988;57:203-9.

43 Ogura Y, Katamoto S, Uchimaru J, et al. Effects of low and high levels of moderate hypoxia on anaerobic energy release during supramaximal cycle exercise. Eur J Appl Physiol 2006;98:41-7.

44 Rhea MR. Determining the magnitude of treatment effects in strength training research through the use of the effect size. J Strength Cond Res 2004; 18:918-20.

45 Nishimura A, Sugita M, Kato K, et al. Hypoxia increases muscle hypertrophy induced by resistance training. Int I Sports Physiol Perform 2010:5:497-508.

46 Manimmanakorn A, Manimmanakorn N, Taylor R, et al. Effects of resistance training combined with vascular occlusion or hypoxia on neuromuscular function in athletes. Eur J Appl Physiol 2013;113:1767-74.

47 Kon M, Ikeda T, Homma T, et al. Effects of acute hypoxia on metabolic and hormonal responses to resistance exercise. Med Sci Sports Exerc 2010;42:1279-85.

48 Melissa L, MacDougall JD, Tarnopolsky MA, et al. Skeletal muscle adaptations to training under normobaric hypoxic versus normoxic conditions. Med Sci Sports Exerc 1997;29:238-43
49 Kawada S, Ishii N. Skeletal muscle hypertrophy after chronic restriction of venous blood flow in rats. Med Sci Sports Exerc 2005;37:1144-50.

50 Friedmann B, Kinscherf R, Borisch S, et al. Effects of low-resistance/high-repetition strength training in hypoxia on muscle structure and gene expression. Pflug Arch Eur J Phy 2003:446:742-51.

51 Manimmanakorn A, Hamlin MJ, Ross JJ, et al. Effects of low-load resistance training combined with blood flow restriction or hypoxia on muscle function and performance in netball athletes. J Sci Med Sport 2013;16:337-42.

52 Morin JB, Edouard P, Samozino P. Technical ability of force application as a determinant factor of sprint performance. Med Sci Sports Exerc 2011;43:1680-8.

53 Komi PV. Stretch-shortening cycle: a powerful model to study normal and fatigued muscle. J Biomech 2000;33:1197-206.

54 Young W, McLean B, Ardagna J. Relationship between strength qualities and sprinting performance. J Sports Med Phys Fitness 1995:35:13-19.

55 Hamlin MJ, Hinckson EA, Wood MR, et al. Simulated rugby performance at 1550-m altitude following adaptation to intermittent normobaric hypoxia. J Sci Med Sport 2008;11:593-9.

56 Arsac LM. Effects of altitude on the energetics of human best performances in 100 m running: a theoretical analysis. Eur J Appl Physiol 2002;87:78-84.

57 Peronnet $F$, Thibault G, Cousineau DL. A theoretical analysis of the effect of altitude on running performance. J Appl Physiol 1991:70:399-404.

58 Girard 0, Micallef JP, Millet GP. Changes in spring-mass model characteristics during repeated running sprints. Eur J App/ Physiol 2011;111:125-34.

59 Girard 0, Racinais S, Kelly L, et al. Repeated sprinting on natural grass impairs vertical stiffness but does not alter plantar loading in soccer players. Eur J Appl Physiol 2011;111:2547-55.

60 Smith KJ, Billaut F. Influence of cerebral and muscle oxygenation on repeated-sprint ability. Eur J App/ Physiol 2010;109:989-99.

61 Bowtell JL, Cooke K, R T. Acute physiological and performance responses to repeated sprints in varying degrees of hypoxia. I Sci Med Sport 2013. In Press.

62 Amann M, Romer LM, Subudhi AW, et al. Severity of arterial hypoxaemia affects the relative contributions of peripheral muscle fatigue to exercise performance in healthy humans. J Physiol 2007;581:389-403.

63 Hogan MC, Richardson RS, Haseler LJ. Human muscle performance and $\mathrm{PCr}$ hydrolysis with varied inspired oxygen fractions: a 31P-MRS study. J App/ Physiol 1999:86:1367-73.

64 Amann M, Goodall S, Twomey R, et al. Altitudeomics: on the consequences of high altitude acclimatization for the development of fatigue during locomotor exercise in humans. J App/ Physiol 2013:115:634-42.

65 Tomlin DL, Wenger HA. The relationship between aerobic fitness and recovery from high intensity intermittent exercise. Sports Med 2001;31:1-11.

66 Bangsbo J, Lindquist F. Comparison of various exercise tests with endurance performance during soccer in professional players. Int I Sports Med 1992;13:125-32.

67 Castagna C, D'Ottavio S. Effect of maximal aerobic power on match performance in elite soccer referees. J Strength Cond Res 2001;15:420-5.

68 Bangsbo J. Energy demands in competitive soccer. J Sports Sci 1994;12: S5-12.

69 Aziz AR, Chia M, Teh KC. The relationship between maximal oxygen uptake and repeated sprint performance indices in field hockey and soccer players. J Sports Med Phys Fitness 2000;40:195-200.

70 Aziz AR, Mukherjee S, Chia MY, et al. Relationship between measured maximal oxygen uptake and aerobic endurance performance with running repeated sprint ability in young elite soccer players. I Sports Med Phys Fitness 2007:47:401-7.

71 Bishop D, Edge J, Goodman C. Muscle buffer capacity and aerobic fitness are associated with repeated-sprint ability in women. Eur J Appl Physiol 2004;92:540-7.

72 Bishop D, Spencer M. Determinants of repeated-sprint ability in well-trained team-sport athletes and endurance-trained athletes. J Sports Med Phys Fitness 2004:44:1-7.

73 Bishop D, Edge J. Determinants of repeated-sprint ability in females matched for single-sprint performance. Eur J Appl Physiol 2006;97:373-9.

74 Dawson B, FitzSimons M, Ward D. The relationship of repeated sprint ability to aerobic power and performance measures of anaerobic work capacity and power. Aust J Sci Med Sports 1993:25:88-93.

75 Bishop D, Girard 0, Mendez-Villanueva A. Repeated-sprint ability_part II: recommendations for training. Sports Med 2011;41:741-56.

76 Girard 0, Mendez-Villanueva A, Bishop D. Repeated-sprint ability-part I: factors contributing to fatigue. Sports Med 2011;41:673-94.

77 Fernandes da Silva J, Guglielmo LGA, Bishop D. Relationship between different measures of aerobic fitness and repeated-sprint ability in elite soccer players. Eur J Appl Physiol 2010;24:2115-21.

78 Levine BD, Stray-Gundersen J. "Living high-training low": effect of moderate-altitude acclimatization with low-altitude training on performance. J Appl Physiol 1997;83:102-12.

79 Stray-Gundersen J, Chapman RF, Levine BD. "Living high-training low" altitude training improves sea level performance in male and female elite runners. J Appl Physiol 2001;91:1113-20. 
80 Clark SA, Quod MJ, Clark MA, et al. Time course of haemoglobin mass during 21 days live high: train low simulated altitude. Eur J App/ Physiol 2009;106:399-406.

81 Gore CJ, Hahn A, Rice A, et al. Altitude training at $2690 \mathrm{~m}$ does not increase total haemoglobin mass or sea level V02max in world champion track cyclists. J Sci Med Sport 1998;1:156-70.

82 McMahon S, Wenger HA. The relationship between aerobic fitness and both power output and subsequent recovery during maximal intermittent exercise. I Sci Med Sport 1998;1:219-27.

83 Faiss R, Leger B, Vesin JM, et al. Significant molecular and systemic adaptations after repeated sprint training in hypoxia. Plos ONE 2013;8:e56522.

84 Thomas C, Sirvent P, Perrey S, et al. Relationships between maximal muscle oxidative capacity and blood lactate removal after supramaximal exercise and fatigue indexes in humans. J Appl Physiol 2004;97:2132-8.

85 Tesch PA, Wright JE. Recovery from short-term exercise: its relation to capillary supply and blood lactate concentrations. Eur J Appl Physiol 1983;53:98-103.

86 Balsom P, Ekblom B, Sjodin B. Enhanced oxygen availablility during high intensity intermittent exercise decreases anaerobic metabolite concentration in blood. Acta Physiol Scand 1994;150:455-6.

87 Mizuno M, Savard GK, Areskog NH, et al. Skeletal muscle adaptations to prolonged exposure to extreme altitude: a role of physical activity? High Alt Med Biol 2008;9:311-17.

88 Green HJ. Muscular adaptations at extreme altitude: metabolic implications during exercise. Int J Sports Med. 1992;13(Suppl 1):S163-5.

89 Green H, Roy B, Grant S, et al. Human skeletal muscle exercise metabolism following an expedition to mount denali. Am J Physiol Regul Integr Comp Physiol 2000;279:R1872-9

90 Geiser J, Vogt M, Billeter R, et al. Training high-living low: changes of aerobic performance and muscle structure with training at simulated altitude. Int I Sports Med 2001;22:579-85.

91 Melissa L, MacDougall JD, Tarnopolsky MA, et al. Skeletal muscle adaptations to training under normobaric hypoxic versus normoxic conditions. Med Sci Sports Exerc 1997;29:238-43.

92 Jacobs RA, Siebenmann C, Hug M, et al. Twenty-eight days at 3454-m altitude diminishes respiratory capacity but enhances efficiency in human skeletal muscle mitochondria. FASEB J 2012;26:5192-200.

93 Jacobs RA, Boushel R, Wright-Paradis $C$, et al. Mitochondrial function in human skeletal muscle following high-altitude exposure. Exp Physiol 2013;98:245-55.

94 Levett DZ, Radford EJ, Menassa DA, et al. Acclimatization of skeletal muscle mitochondria to high-altitude hypoxia during an ascent of Everest. FASEB J 2012;26:1431-41.

95 Hoppeler $\mathrm{H}$, Vogt M, Weibel ER, et al. Response of skeletal muscle mitochonrial to hypoxia. Exp Physiol 2003;88:109-19.

96 Terrados N, Jansson E, Sylven C, et al. Is hypoxia a stimulus for synthesis of oxidative enzymes and myoglobin?. J Appl Physiol 1990;68:2369-72.

97 Tonkonogi M, Sahlin K. Rate of oxidative phosphorylation in isolated mitochondria from human skeletal muscle: effect of training status. Acta Physio/ Scand 1997; 161:345-53.

98 Larsen S, Nielsen J, Hansen CN, et al. Biomarkers of mitochondrial content in skeletal muscle of healthy young human subjects. J Physio/ 2012;590(Pt 14):3349-60.

99 Gore CJ, Clark SA, Saunders PU. Nonhematological mechanisms of improved sea-level performance after hypoxic exposure. Med Sci Sports Exerc 2007;39:1600-9.

100 Siebenmann C, Robach P, Jacobs RA, et al. "Live high-train low" using normobaric hypoxia: a double-blinded, placebo-controlled study. J App/ Physiol. 2012;112:106-17.

101 Green HJ. Altitude acclimatization, training and performance. J Sci Med Sport 2000;3:299-312.

102 Robach P, Siebenmann C, Jacobs RA, et al. The role of haemoglobin mass on VO (2)max following normobaric 'live high-train low' in endurance-trained athletes. $\mathrm{Br}$ J Sports Med 2012;46:822-7.

103 Saltin B, Kiens B, Savard G, et al. Role of hemoglobin and capillarization for oxygen delivery and extraction in muscular exercise. Acta Physiol Scand Supp/ 1986;556:21-32.

104 Mendez-Villanueva A, Edge J, Suriano R, et al. The recovery of repeated-sprint exercise is associated with $\mathrm{PCr}$ resynthesis, while muscle $\mathrm{pH}$ and EMG amplitude remain depressed. PLOS ONE 2012;7:e51977.

105 Bogdanis GC, Nevill ME, Boobis LH, et al. Contribution of phosphocreatine and aerobic metabolism to energy supply during repeated sprint exercise. J Appl Physiol 1996;80:876-84.

106 Bogdanis GC, Nevill ME, Boobis LH, et al. Recovery of power output and muscle metabolites following $30 \mathrm{~s}$ of maximal sprint cycling in man. J Physiol (Lond) 1995;482:467-80

107 Spencer M, Bishop D, Dawson B, et al. Metabolism and performance in repeated cycle sprints: active versus passive recovery. Med Sci Sports Exerc 2006:38:1492-9.

108 Spencer M, Dawson B, Goodman C, et al. Performance and metabolism in repeated sprint exercise: effect of recovery intensity. Eur J Appl Physiol 2008; 103:545-52.
109 Trump ME, Heigenhauser GJF, Putman CT, et al. Importance of muscle phosphocreatine during intermittent maximal cycling. J App/ Physiol 1996:80:1574-80.

110 Greenhaff PL, Bodin K, Soderlund K, et al. Effect of oral creatine supplementation on skeletal muscle phosphocreatine resynthesis. Am J Physiol 1994;266:E725-30.

111 Skare OC, Skadberg O, Wisnes AR. Creatine supplementation improves sprint performance in male sprinters. Scand J Med Sci Sports 2001;11:96-102.

112 Preen D, Dawson B, Goodman C, et al. The effect of oral creatine supplementation on 80 minutes of repeated-sprint exercise. Med Sci Sports Exerc 2001:33:814-25.

113 Wiroth J, Bermon S, Andrei S, et al. Effects of oral creatine supplementation on maximal pedalling performance in older adults. Eur J Appl Physiol 2001;84:533-9.

114 Van Loon LJC, Oosterlaar AM, Hartgens F, et al. Effects of creatine loading and prolonged creatine supplementation on body composition, fuel selection, sprint and endurance performance in humans. Clin Sci (Lond) 2003;104:153-62.

115 Cox G, Mujika I, Tumilty D, et al. Acute creatine supplementation and performance during a field test simulating match play in elite female soccer players. Int J Sport Nutr Exerc Metab 2002;12:33-46.

116 McCully KK, Fielding RA, Evans WJ, et al. Relationships between in vivo and in vitro measurements of metabolism in young and old human calf muscles. J Appl Physiol 1993;75:813-19.

117 Radda GK, Bore PJ, Gadian DG, et al. 31P NMR examination of two patients with NADH-CoQ reductase deficiency. Nature 1982;295:608-9.

118 Bishop D, Claudius B. Effects of induced metabolic alkalosis on prolonged intermittent-sprint performance. Med Sci Sports Exerc 2005;37:759-67.

119 Bishop D, Edge J, Davis C, et al. Induced metabolic alkalosis affects muscle metabolism and repeated-sprint ability. Med Sci Sports Exerc 2004;36:807-13.

120 Lavender G, Bird SR. Effect of sodium bicarbonate ingestion upon repeated sprints. Br J Sports Med 1989;23:41-5.

121 Price $M$, Moss $P$, Rance $S$. Effects of sodium bicarbonate ingestion on prolonged intermittent exercise. Med Sci Sports Exerc 2003;35:1303-08.

122 Bishop D. Dietary supplements and team-sport performance. Sports Med 2010;40:995-1017.

123 Edge J, Bishop D, Hill-Haas S, et al. Comparison of muscle buffer capacity and repeated-sprint ability of untrained, endurance-trained and team-sport athletes. Eur J Appl Physiol 2006;96:225-34.

124 Gaitanos GC, Nevill ME, Brooks S, et al. Repeated bouts of sprint running after induced alkalosis. J Sports Sci 1991;9:355-69.

125 Tan F, Polglaze T, Cox G, et al. Effects of induced alkalosis on simulated match performance in elite female water polo players. Int I Sport Nutr Exerc Metab 2010;20:198-205.

126 Bogdanis GC, Nevill ME, Lakomy HKA, et al. Power output and muscle metabolism during and following recovery from 10 and $20 \mathrm{~s}$ of maximal sprint exercise in humans. Acta Physiol Scand 1998;163:261-72.

127 Harris RC, Tallon MJ, Dunnett M, et al. The absorption of orally supplied $\beta$-alanine and its effect on muscle carnosine synthesis in human vastus lateralis. Amino Acids 2006:30:279-89.

128 Hill CA, Harris RC, Kim HJ, et al. Influence of $\beta$-alanine supplementation on skeletal muscle carnosine concentrations and high intensity cycling capacity. Amino Acids 2007;32:225-33

129 Saunders B, Sunderland C, Harris RC, et al. Beta-alanine supplementation improves YoYo intermittent recovery test performance. J Int Soc Sports Nutr 2012;9:39.

130 Krustrup P, Mohr M, Amstrup T, et al. The yo-yo intermittent recovery test: physiological response, reliability, and validity.[see comment]. Med Sci Sports Exerc 2003:35:697-705.

131 Krustrup $\mathrm{P}$, Mohr M, Ellingsgaard $\mathrm{H}$, et al. Physical demands during an elite female soccer game: Importance of training status. Med Sci Sports Exerc 2005:37:1242-8.

132 Sweeney KM, Wright GA, Glenn Brice A, et al. The effect of beta-alanine supplementation on power performance during repeated sprint activity. I Strength Cond Res 2010;24:79-87.

133 Gore CJ, Hahn AG, Aughey RJ, et al. Live high:train low increases muscle buffer capacity and submaximal cycling efficiency. Acta Physio/ Scand 2001;173: 275-86.

134 Clark S, Aughey R, Gore CJ, et al. Effects of live high, train low hypoxic exposure on lactate metabolism in trained humans. J App/ Physiol 2004;96:517-25.

135 Saltin B, Kim CK, Terrados N, et al. Morphology, enzyme activities and buffer capacity in leg muscles of Kenyan and Scandinavian runners. Scand J Med Sci Sports 1995:5:222-30.

136 Edge J, Bishop D, Goodman C. The effects of training intensity on muscle buffer capacity in females. European Journal of Applied Physiology 2006;96:97-105.

137 Edge J, Bishop D, Goodman C. Effects of chronic NaHCO3 ingestion during interval training on changes to muscle buffer capacity, metabolism, and short-term endurance performance. J App/ Physiol 2006;101:918-25. 